\title{
Developmental Psychology, Aged
}

National Cancer Institute

\section{Source}

National Cancer Institute. Developmental Psychology, Aged. NCI Thesaurus. Code C18739.

Developmental psychology research focusing on the years after age 65 . 